\title{
LXXXIV.-Oxymercuric Perchlorates and the Action of Alcohol on Mercury Perchlorates.
}

\section{By Masumi Chikashigé.}

THE following statements have already been published, in part by Serullas in 1830 and in part by the author in 1895 (Trans., 67, 1013). Mercuric perchlorate crystallises with six mols. of water, is exceedingly soluble in water, and very deliquescent; it partly decomposes with hot water, and loses both acid and water when left in a desiccator. Alcohol converts it into a white basic compound and gives with its aqueous solution an orange precipitate consisting mainly of mercuric oxide. The white basic compound also leaves a little mercuric oxide when acted on by water. An apparently detinite, although amorphous, oxymercuric perchlorate, $\mathrm{O}_{2} \mathrm{Hg}_{3}\left(\mathrm{ClO}_{4}\right)_{2}$, is obtained by heating the normal salt slowly to $150^{\circ}$. Towards both water and alcohol, mercurous perchlorate, which crystallises with four mols. of water, behaves in somewhat the same way as the mercuric salt, except that alcohol has no immediate effect on its aqueous solution. A mixture of mercurous and mercuric perehlorates is obtained when an alcoholic solution of the mercuric salt is boiled and concentrated by evaporation. The author has since made a fuller and a quantitative examination of the subject, the results of which are described in the present paper. Several new salts have been prepared.

Hydrated Oxymercuric Perchlorate, $\mathrm{OH}_{3}\left(\mathrm{ClO}_{4}\right)_{4}, 12 \mathrm{H}_{2} \mathrm{O}$.---If, instead of just neutralising perchloric acid with mercuric oxide, the solution 
of the acid is digested with excess of the oxide and then filtered through asbestos and concentrated by evaporation on the water-bath to a sufficient extent, it will, when left in a desiccator to cool and evaporate, deposit prismatic crystals resembling those of the normal salt except in being somewhat opaque. Dried under cover on a porous tile, the salt has been found to be very soluble in water, leaving only a very little yellow mercuric oxide undissolved, but when its solution is evaporated the salt gradually decomposes into mercuric oxide and the normal perchlorate. The mercury found in it was 48.80 per cent., the calculated amount being 48.76.

Action of Alcohol in the Cold on Mercury Perchlorates.-When either mercuric or mercurous perchlorate is treated with cold alcohol, most of the salt goes into solution. The author now doubts whether the residue is basic to any considerable extent, or much else than anhydrous or at least dehydrated normal salt. In the case of the mercuric salt, the white substance quickly dissolves when the alcohol is being heated to boiling, whilst in the case of the mercurous salt it almost completely dissolves when boiled for a few minutes with the alcohol. That both residues are decomposed when washed with water is no proof of their being basic, because water itself decomposes the hydrated normal salts to some extent. It has not been possible to get enough of the mercuric compound in a sufficiently pure state for analysis, but the mercurous compound has given about 63 per cent. of mercury, the calculation for anhydrous mercurous perchlorate requiring 66.8 and for the hydrated salt $59 \cdot 6$.

Action of Boiling Alcohol on Mercuric Perchlorate.-On boiling the solution of mercuric perchlorate with alcohol, the insoluble matter goes quickly into solution in the manner just indicated, but its dissolution is soon followed by the production of a scanty flocculent precipitate, which, on continuing the boiling, gradually gives place to a very small quantity of granular precipitate rapidly settling at the bottom of the flask. During the boiling, much aldehyde is produced and most of the mercury perchlorate is changed into mercurous perchlorate, and without the formation of any chloride whatever. The change of the mercuric into mercurous salt is never complete. After filtering from the generally insignificant amount of precipitated mercuric salts, the addition of hydrochloric acid gives quantities of mercurous chloride amounting to 91 to 92 per cent. of the total mercury taken as normal mercuric salt, namely, $35 \cdot 9,35 \cdot 1,36 \cdot 2$ per cent., as against $39 \cdot 45$ per cent. in the normal mercuric salt. The rest of the mercury which remains in the mother liquor and in the small precipitates filtered off is entirely in the mercuric state.

If the alcoholic solution is diluted with water and evaporated, it deposits, on cooling, principally the hydrated mercurous perchlorate. 


\section{CHIKASHIGÉ: OXYMERCURIC PERCHLORATES AND THE}

When, without addition of water, the alcoholic solution is evaporated over briskly boiling water, the mercurous salt is for the most part decomposed into metallic mercury and oxymercuric perchlorates, some perchloric acid no doubt remaining in the solution, for the basic salt is insoluble in acids. When, instead of proceeding in either of these ways, the alcoholic solution is evaporated at a gentle heat, it deposits, towards the end, needle-shaped crystals, coloured slightly grey through contamination with a very little metallic mercury. Some of these crystals were weighed out for analysis, dissolved in water, and filtered from metallic mercury. From the clear solution, mercurous chloride was precipitated and weighed. After removal of all the mercury from another portion of the salt the perchloric acid was precipitated and weighed with the usual precautions as potassium salt.

\begin{tabular}{|c|c|c|c|}
\hline & & & $\underset{\text { requires }}{10\left(\mathrm{HgClO}_{4}\right)_{2}, \mathrm{Hg}\left(\mathrm{ClO}_{4}\right)_{2}}$ \\
\hline $\mathrm{ClO}_{4} \ldots \ldots \ldots$ & $34 \cdot 80$ & - & 34.25 \\
\hline $\mathrm{Hg}^{\mathrm{I}^{4}} \ldots \ldots \ldots \ldots$ & - & $62 \cdot 37$ & $62 \cdot 62$ \\
\hline $\mathrm{Hg}^{\mathrm{II}} .$. & $\ldots$ & - & $3 \cdot 13$ \\
\hline
\end{tabular}

The existence of $10\left(\mathrm{HgClO}_{4}\right)_{2}, \mathrm{Hg}\left(\mathrm{ClO}_{4}\right)_{2}$ as an individual substance is open to doubt, but it may be pointed out that Rây has found that mercurous nitrite, when treated with water, deposits mercury and tends to form the compound $\left(\mathrm{HgNO}_{2}\right)_{2}, 4 \mathrm{Hg}\left(\mathrm{NO}_{2}\right)_{2}$, not more than 78 per cent. of the mercurous nitrite becoming converted into mercuric nitrite (Trans., 1897, 71, 340).

Action of Boiling Alcohol on Hydrated Oxymercuric Perchlorate.When hydrated oxymercuric perchlorate is boiled with alcohol, there is formed, at first, an abundant flocculent precipitate, but as the boiling continues, this gradually gives place to a granular precipitate quickly settling down, which is not changed by longer boiling with alcohol. The mother liquor of these precipitates contains much mercurous perchlorate, thus resembling the solution obtained by boiling the normal salt with alcohol. The flocculent and the granular precipitates are distinct oxymercuric perchlorates.

Anhydrous 1/3-Basic Oxymercuric Perchlorate, $\mathrm{OHg}_{3}\left(\mathrm{ClO}_{4}\right)_{4}$. -When the flocculent, white precipitate produced on boiling the hydrated 1/3-basic oxymercuric perchlorate (p. 822) with alcohol appeared to be close to its maximum quantity and had not begun to give place to the dense granular precipitate, it was filtered off, washed well with water, and dried in a steam oven. It is insoluble in either hydrochloric or nitric acid, but is decomposed and dissolved by a mixture of the two. Heated over the Bunsen flame, it remains unchanged until its temperature reaches nearly to that of dull redness, when it seems to burn explosively with a feeble violet flame and leaves a red residue of 
mercuric oxide. It behaves, therefore, when heated, much like mercury fulminate, but in a far less violent way. The percentage of mercury was found to be $60 \cdot 35$, whereas theory requires $59 \cdot 18$.

$\beta$-2/3-Basic Oxymercuric Perchlorate, $\mathrm{O}_{2} \mathrm{Hg}_{3}\left(\mathrm{ClO}_{4}\right)_{2}$-The white, granular precipitate, which remains when the alcoholic solution of the hydrated $1 / 3$-basic oxymercuric salt is boiled until there is no sign of further decomposition being in progress, was collected and prepared for examination in the same way as the foregoing salt; it is called the $\beta$-salt in order to distinguish it from the $2 / 3$-basic oxymercuric perchlorate, described by the author in his first paper as being produced by heating the normal salt. Its analysis gave 70.73 and again $71 \cdot 15$ per cent. of mercury, whereas the calculated amount is $72 \cdot 21$.

In solubility in water and single acids it resembles the $1 / 3$-basic salt, and in this respect differs from the $a-2 / 3$-basic salt, which is decomposed by water and dissolved by acids. Up to nearly a red heat, the $\beta-2 / 3$-basic salt, like the $a-2 / 3$-basic salt and the $1 / 3$-basic salt, is quite stable. But at about a dull red heat it detonates with great violence and entirely disappears. The violence of its detonation is certainly much greater than that of the detonation of an equal weight of mercury fulminate. A milligram of the salt shattered the end of a nickel spatula on which it was exploded. The $a$-salt, on the other hand, decomposes without the least explosion at a temperature nearly sufficient to decompose mercuric oxide. The $\beta$-salt also detonates by percussion. Ordinary percussion caps have been found to detonate satisfactorily when charged in the usual way with a mixture of 37.5 parts each of the $\beta$-salt and potassium chlorate to 25 parts of antimony sulphide.

Vature of the Action of Alcohol on Mercury Perchlorates.-From what has been stated, it seems fairly certain that alcohol in the first place removes the water from the three hydrated salts : the mercuric and the 1/3-basic oxymercuric perchlorates and the mercurous perchlorate; then it acts, at a boiling heat, on mercuric perchlorate as a reducing agent, converting it into mercurous perchlorate and perchloric acid :

$$
2 \mathrm{Hg}\left(\mathrm{ClO}_{4}\right)_{2}+\mathrm{C}_{2} \mathrm{H}_{6} \mathrm{O}=\left(\mathrm{HgClO}_{4}\right)_{2}+2 \mathrm{HClO}_{4}+\mathrm{C}_{2} \mathrm{H}_{4} \mathrm{O} \text {. }
$$

The aldehyde and the perchloric acid volatilise, the latter possibly in part as its ester, but probably not, in accordance with Roscoe's experiments as to the behaviour of the acid with alcohol (Proc. Roy. Soc., 1862, 11, 502 ; J. Chem. Soc., 1862, 15, 213).

The alcohol evidently acts in such a way on the $1 / 3$-basic oxymercuric salt as to resolve it into normal mercuric and $\beta$-2/3-basic oxy= mercuric perchlorates; then by reduction the alcohol converts most of the former into perchloric acid and mercurous perchlorate, in the manner just shown. The very slight production of oxymercurie

VOL. LXXXVII.

$3 \mathrm{~K}$ 
perchlorate when the alcoholic solution of either mercuric or mercurous perchlorate is boiled is certainly to be attributed to hydrolysis; at the same time, the mercurous salt becomes, although to a small extent only, resolved into metal and mercuric salt.

In conclusion, the author wishes to express his warmest thanks to Dr. Edward Divers for undertaking the thorough revision of the paper.

IMPERIAL UNIYERSITY OF KYoTO, JAPAN. 